\title{
Closure of mitral paravalvular defects without performing an arteriovenous loop: a case series of fourteen patients
}

\author{
Alev Kilicgedik, Sabahattin Gunduz, Ali Fedakar, Hasan Sunar, Akin Izgi, Muhsin Türkmen, Mehmet Ozkan, \\ Cevat Kirma
}

Kartal Kosuyolu Heart Institution, Training Hospital, Istanbul, Turkey

Adv Interv Cardiol 2017; 13, 4 (50): 307-312

DOI: https://doi.org/10.5114/aic.2017.71612

\begin{abstract}
A bstract
Introduction: The arteriovenous (AV) loop is recommended when further support is needed during paravalvular leak (PVL) closure. Aim: We report the feasibility and safety of mitral PVL closure without constructing an AV loop, based on a single-centre experience.

Material and methods: Fourteen patients with mitral valve replacement (MVR) who had New York Heart Association (NYHA) class III-IV dyspnoea or NYHA class II symptoms with significant haemolytic anaemia caused by severe or moderate-to-severe paravalvular regurgitation and who underwent transcatheter PVL closure (TPVLC) between May 2014 and February 2017 were enrolled.

Results: In total, 15 PVL procedures and 19 device deployments were performed. The patients had one $(n=10)$, three $(n=1)$ or four $(n=1)$ devices for closure at the time of the procedure; one patient had two devices from two procedures at different times with different access ways. Nineteen devices (10 (66.6\%) via transseptal access; 4 (26.6\%), transapical access; and 1 (6.6\%), retrograde access) were deployed successfully without making an AV loop.

Conclusions: The TPVLC is a less invasive and effective alternative to surgery in symptomatic patients with significant PVLS and high operational risks. The success rates are satisfactory, with improving techniques and devices. Procedural success without using an AV loop can be achieved with reduced costs, fluoroscopic times and complications.
\end{abstract}

Key words: mitral regurgitation, paravalvular leak, percutaneous mitral valvuloplasty.

\section{Introduction}

Paravalvular leak (PVL) is an uncommon but serious complication of mechanical or bioprosthetic surgical valve replacement (e.g. mitral valve replacement - MVR) and may be seen in $2-12 \%$ of patients after MVR [1]. Most PVLs are clinically silent, but $1-5 \%$ of patients become symptomatic because of heart failure, haemolysis or both and require re-operation [2, 3]. Although redo surgery has been accepted as a class I recommendation in the guidelines, transcatheter PVL closure seems to be a feasible alternative to surgery in patients with a high surgical risk and suitable anatomic features [4]. In many registries and metaanalyses, the safety and efficacy of PVL closure has been reported, with a reasonable rate of procedural success and a low rate of major complications [5-7]. Because there are no specific devices for PVL closure and because of the heterogeneity in the size and shape of the defects, variable vascular and septal occluder devices can be used by the operators [1].
There are three approaches for closure: transfemoral, transseptal and transapical [8]. Each approach can be chosen according to the location, shape and size of defects, as per the expertise of the operator. In all approaches, an arteriovenous (AV) loop is recommended when further support is needed, and if so, the wire can be snared and externalised via a femoral artery sheath; however, each of these procedures is time consuming and costly and increases the risk of complications $[8,9]$.

\section{Aim}

We report the feasibility and safety of mitral PVL closure without constructing an AV loop in a prospective registry from a single centre.

\section{Material and methods}

Fourteen patients with MVR with or without aortic valve replacement (AVR) who had New York Heart As-

Corresponding author:

Alev Kilicgedik MD, Kartal Kosuyolu Heart Institution, Training Hospital, 34865 Istanbul, Turkey, e-mail: akilicgedik@yahoo.com Received: 8.08.2017, accepted: 28.10.2017. 
sociation (NYHA) class III-IV dyspnoea or NYHA class II symptoms with significant haemolytic anaemia caused by severe or moderate-to-severe paravalvular regurgitation and who underwent a transcatheter PVL closure (TPVLC) procedure between May 2014 and February 2017 were enrolled in this study retrospectively. Symptomatic haemolysis was defined as haemolytic anaemia (haemoglobin $\leq 10 \mathrm{~g} / \mathrm{dl}$, lactate dehydrogenase $\geq 600 \mathrm{mg} / \mathrm{dl}$, haptoglobin $\leq 50 \mathrm{mg} / \mathrm{dl}$ and reticulocytosis $>2 \%$ ) requiring $2 \mathrm{U}$ of blood transfusions and/or erythropoietin injections within 90 days to maintain a haemoglobin level of $\geq 10 \mathrm{~g} / \mathrm{dl}$, without any other source of blood loss [3].

All cases were discussed in a Cardiology and Cardiovascular council and were recommended for PVL closure because of high surgical risks. Operational high risk was defined based on the Logistic EuroSCORE (http://www. EuroSCORE.org/calc.html) and the Society of Thoracic Surgeons score (http://209.220.160.181/STSWebRiskCalc261). The local ethics committee approved this study.

All procedures were performed under general anaesthesia. Two-dimensional (2D) and real-time three-dimensional (3D) transoesophageal echocardiography (TEE) were performed before and during the operation, using an iE33 ultrasound system (Philips Medical Systems, Andover, Massachusetts) with a fully sampled 3D matrix array TEE transducer. The location, size, shape and severity of the paravalvular regurgitation were evaluated before the procedure using 2D and 3D TEE, according to the current guidelines [10]. The mitral valve is viewed as a clock face, and the leak origin is defined by the position on the clock (Figure 1) from the left atrial (LA) perspective (termed the 'surgeon's view') [1]; 2D and 3D TEE were used to intraprocedurally guide the placement of the transseptal puncture, passage of the guidewire and cath-

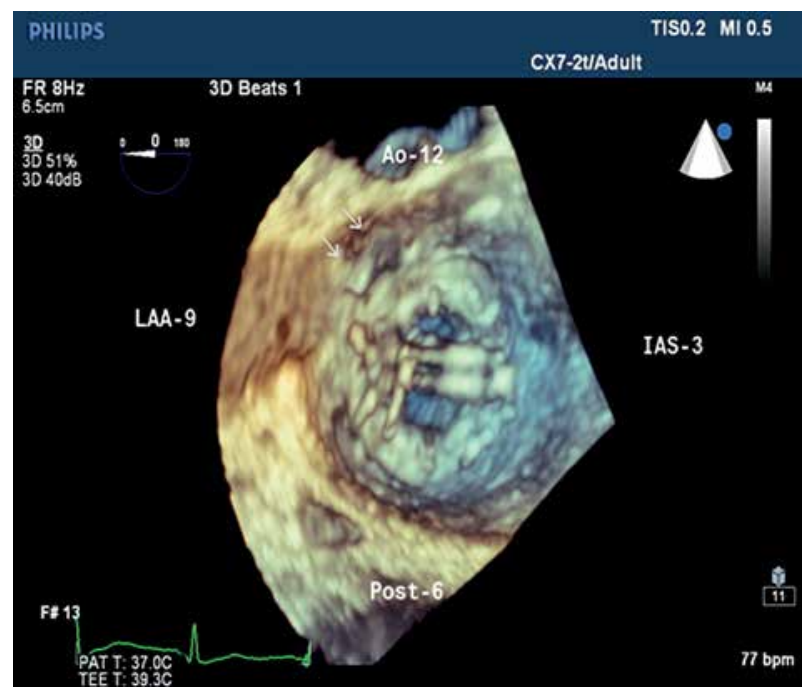

Figure 1. Anatomic mitral view depicting the location and extent of the sites of paravalvular mitral regurgitation

Ao - aorta, LAA - left atrial appendage, IAS - interatrial septum and arrows: paravalvular defect. eter through the defect, proper positioning of the opened occluder, proper seating of the device and evaluation of the function of the prosthesis and residual regurgitation.

Antibiotic prophylaxis was administered.

\section{Procedure}

Transseptal Access: For transseptal PVL closure, a transseptal puncture was performed according to the location of the PVL (with a higher puncture for laterally located PVLs and a lower and more posterior puncture for medially located PVLs); once the atrial septum was punctured, an Agilis NxT steerable guide catheter (St Jude Medical) was advanced to the LA. An angled catheter (mostly a 5-Fr vertebral or 4-Fr angled Glide catheter (Terumo Medical)) was advanced into the LA via the Agilis for facilitating the passage of the wire from the PVL. Then, a 0.035-inch angled hydrophilic wire (Poseidon, SP Medical A/S) was passed through the PVL. Once the defect was passed, the hydrophilic wire was replaced with a super-stiff guidewire (Amplatz Super Stiff, J-TIP, Boston Scientific) via the angled catheter. The tip of the stiff guidewire was reshaped into a circle for greater stability in the left ventricle, as in the transaortic valve implantation procedure; in all cases, the AV loop was not performed. The Agilis was then removed, and the interatrial septum was dilated. Depending on the size and type of closure device, a 6- or 7-Fr Amplatz TorqueVue delivery sheath was advanced to the LA, and the device of choice was then deployed to the PVL.

Transapical access: For transapical access, a mini-thoracotomy was first performed. The apex was punctured under direct vision. A 7-Fr sheath was inserted and fixed. Under fluoroscopy and TEE guidance, the defect was crossed using a hydrophilic guidewire through a variety of catheters, including the left Amplatz (AL 1), right Judkins and multipurpose (MP) catheter. After crossing the $P V L$, the hydrophilic guidewire was exchanged for a stiff wire. No AV loop was performed. The selected occluder was deployed through the long sheath.

Retrograde access: Through the femoral artery, a 0.035 -inch hydrophilic guidewire was advanced to the $P V L$ via a guiding catheter (i.e. AL-1 or MP). Once the PVL was crossed, to provide support, the hydrophilic guidewire was exchanged for a stiffer wire via a microcatheter. Then, the delivery sheath was advanced over the stiff wire, and the device of choice was deployed to the PVL.

Technical success was considered as the correct deployment of the device without significant residual regurgitation, new prosthetic valve malfunction or interference with other cardiac structures.

After the procedure was completed, patients were closely observed in the coronary care unit. Before discharge, all patients received control transthoracic echocardiography, and the therapeutic international normalised ratio level was assessed. 


\section{Statistical analysis}

Data management and analysis were performed using SPSS Statistics version 17.0 (SPSS Inc., Chicago, IL). Continuous variables are expressed as mean and standard deviation (SD) or median and interquartile range (IRQ), according to the variable distribution. Normal distributions were confirmed using the Kolmogorov-Smirnov test.

\section{Results}

The characteristics of patients' clinical and paravalvular defects are shown in Tables I and II. The mean age of the study population was $58.7 \pm 12.7$ years, and the
NYHA classes were III and III-IV. Symptomatic haemolysis was present in almost all patients (85.7\%). Half of the patients had undergone $>1$ cardiac operation; half of them had undergone AVR and MVR procedures, and the other half had received MVR operation only. The predicted surgical risk based on the logistic EuroSCORE was $15.6 \pm 15.5$

A total of 14 patients were treated with $15 \mathrm{PVL}$ and 19 device deployment procedures. Ten patients had one device, 1 patient had four devices and 1 patient had three devices for closure at the time of the procedure; 1 patient had two devices from two procedures performed at different times with different access ways (trans-

Table I. Characteristics of patients' clinical status and paravalvular defects

\begin{tabular}{|c|c|c|c|c|c|c|c|c|c|}
\hline Patients & $\begin{array}{l}\text { NYHA } \\
\text { class }\end{array}$ & Indication & HGB & LDH & $\begin{array}{l}\text { AVR + } \\
\text { MVR }\end{array}$ & Device sizes & Access way & Location & $\begin{array}{l}\text { Catheters to pass } \\
\text { the defects }\end{array}$ \\
\hline 1 & III & Haemolysis & 8.1 & 1866 & $\begin{array}{l}\text { MVR } \\
\text { only }\end{array}$ & $10 \times 3$ AVP III & Transseptally & Anterolateral & Agilis, 7 Fr MP, 5 Fr vertebral \\
\hline 2 & III & $\begin{array}{l}\text { Haemolysis } \\
+ \text { HF }\end{array}$ & 10.6 & 1019 & + & $4 \times 8$ AVP III & Transseptally & $\begin{array}{l}\text { Posterolat- } \\
\text { eral }\end{array}$ & $\begin{array}{l}\text { Agilis, } 7 \text { Fr MP, } \\
5 \text { Fr vertebral }\end{array}$ \\
\hline 3 & IV & $\begin{array}{c}\text { HF } \\
+ \text { haemolysis }\end{array}$ & 9.5 & 1098 & + & $10 \times 5$ AVP III & Transseptally & $\begin{array}{l}\text { Anterolateral } \\
\text { and medial }\end{array}$ & Agilis, 7 Fr RJ \\
\hline 4 & III & Haemolysis & 8.7 & 2238 & + & $\begin{array}{c}6 \times 3,10 \times 5 \\
8 \times 4 \text { AVPIII } \\
\text { and } 6 \times 6 \text { ADO }\end{array}$ & Transapically & Posterior & 7 Fr MP \\
\hline 5 & III & $\begin{array}{c}\text { HF } \\
+ \text { haemolysis }\end{array}$ & 10.5 & 857 & $\begin{array}{l}\text { MVR } \\
\text { only }\end{array}$ & $6 \times 3$ AVP III & Transseptally & Anterolateral & Agilis, 7 Fr MP, 5 Fr vertebral \\
\hline 6 & III & $\begin{array}{l}\text { Haemolysis } \\
+ \text { HF }\end{array}$ & 10.7 & & + & $10 \times 3$ AVP III & Transapically & $\begin{array}{l}\text { Posterome- } \\
\text { dial }\end{array}$ & Agilis, Minnie, 7 Fr RJ \\
\hline 7 & III & $\mathrm{HF}$ & 11.2 & 852 & + & $\begin{array}{c}10 \times 5 \text { and } \\
12 \times 5 \text { AVP III }\end{array}$ & Transseptally & Lateral & Agilis, 7 Fr MP, 5 Fr vertebral \\
\hline 8 & III & Haemolysis & 8.6 & 1177 & $\begin{array}{l}\text { MVR } \\
\text { only }\end{array}$ & $12 \times 5$ Occlutech & Transseptally & $\begin{array}{l}\text { Posterolat- } \\
\text { eral }\end{array}$ & Agilis, 5 Fr vertebral \\
\hline 9 & III-IV & $\begin{array}{l}\text { HF } \\
+ \text { haemolysis }\end{array}$ & 9 & 1585 & + & $6 \times 3$ AVP III & Transseptally & Lateral & Agilis, 7 Fr RJ, 5 Fr vertebral \\
\hline 10 & III & $\begin{array}{c}\text { HF } \\
+ \text { haemolysis }\end{array}$ & 10.5 & 504 & $\begin{array}{l}\text { MVR } \\
\text { only }\end{array}$ & $\begin{array}{c}14 \times 5,6 \times 3 \\
\text { and } 8 \times 4 \text { AVP III }\end{array}$ & Transseptally & Medial & Agilis, 7 Fr MP, 5 Fr vertebral \\
\hline 11 & III & $\begin{array}{l}\text { Haemolysis } \\
+ \text { HF }\end{array}$ & 9.8 & 418 & $\begin{array}{l}\text { MVR } \\
\text { only }\end{array}$ & $10 \times 3$ AVP III & Transseptally & Lateral & Agilis, 7 Fr RJ, 5 Fr vertebral \\
\hline 12 & III & HF & 12.2 & 821 & $\begin{array}{l}\text { MVR } \\
\text { only }\end{array}$ & $8 \times 4$ AVP III & Transseptally & Lateral & Agilis, 7 Fr RJ, 5 Fr vertebral \\
\hline 13 & III-IV & $\begin{array}{l}\text { Haemolysis } \\
+ \text { HF }\end{array}$ & 9.1 & 2813 & + & $\begin{array}{c}8 \times 4 \\
\text { and } 6 \times 3 \text { AVP II }\end{array}$ & Transapically & $\begin{array}{l}\text { Posterome- } \\
\text { dial }\end{array}$ & $7 \mathrm{Fr} \mathrm{RJ}$ \\
\hline 14 & III & $\begin{array}{l}\text { Haemolysis } \\
+\mathrm{HF}\end{array}$ & 10.8 & 872 & MVR & $\begin{array}{c}8 \times 4 \\
\text { and } 8 \times 4 \text { AVP III }\end{array}$ & $\begin{array}{c}\text { Transseptally } \\
\text { vs. retro- } \\
\text { gradely }\end{array}$ & $\begin{array}{c}\text { Anterolateral } \\
\text { and antero- } \\
\text { medial }\end{array}$ & $\begin{array}{c}\text { Agilis, } 7 \text { Fr RJ, } 5 \text { Fr vertebral, } \\
\text { Left Amplatz } 2\end{array}$ \\
\hline
\end{tabular}

HGB - haemoglobin levels (mg/dl), LDH - lactate dehydrogenase (U/l). Catheters to pass the defects: Agilis - Agilis NxT steerable introducer, St. Jude Medical; 7 Fr RJ - 7 French right Judkins, launcher guiding catheter, 5 Fr vertebral - 5 French VER Super Torque, Cordis, 7 Fr MP - 7 French multipurpose A1, Boston Scientific, Minnie - Minnie support Catheter, Vascular Solutions Inc., 6 Fr - 6 French left Amplatz 2, Boston Scientific. Device sizes $\leq 10$ Amplatzer vascular plug III (AVPIII) were delivered via 7 French guiding catheters or 7 French AMPLATZER TorqVue 2 delivery sheaths. Device sizes $>10$ AVP III were delivered via 9 French AMPLATZER TorqVue 2 delivery sheaths. 
septal access for anterolaterally located PVL and retrograde access for anteromedially located PVL; Figure 2). A total of 19 devices (10 (66.6\%) via transseptal access, 4 (26.6\%) via transapical access and 1 (6.6\%) via retrograde access) were deployed successfully, without constructing an AV loop (Figure 3). In 1 case, because

Table II. Clinical characteristics of the patient group

\begin{tabular}{lc} 
Parameter & Patient group \\
\hline Age & $58.7 \pm 12.7$ \\
\hline Gender, F, $n(\%)$ & $6(42.8)$ \\
\hline HT, $n(\%)$ & $6(42)$ \\
\hline DM, $n(\%)$ & $4(28.5)$ \\
\hline KBY, $n(\%)$ & $2(14)$ \\
\hline Hgb, mean \pm SD & $9.97 \pm 1.19$ \\
\hline LDH, mean \pm SD & $1240 \pm 699$ \\
\hline Log EuroSCORE II & $12.75(5.8-19.7)$ \\
\hline LVEF, mean \pm SD & $49.4 \pm 13.7$
\end{tabular}
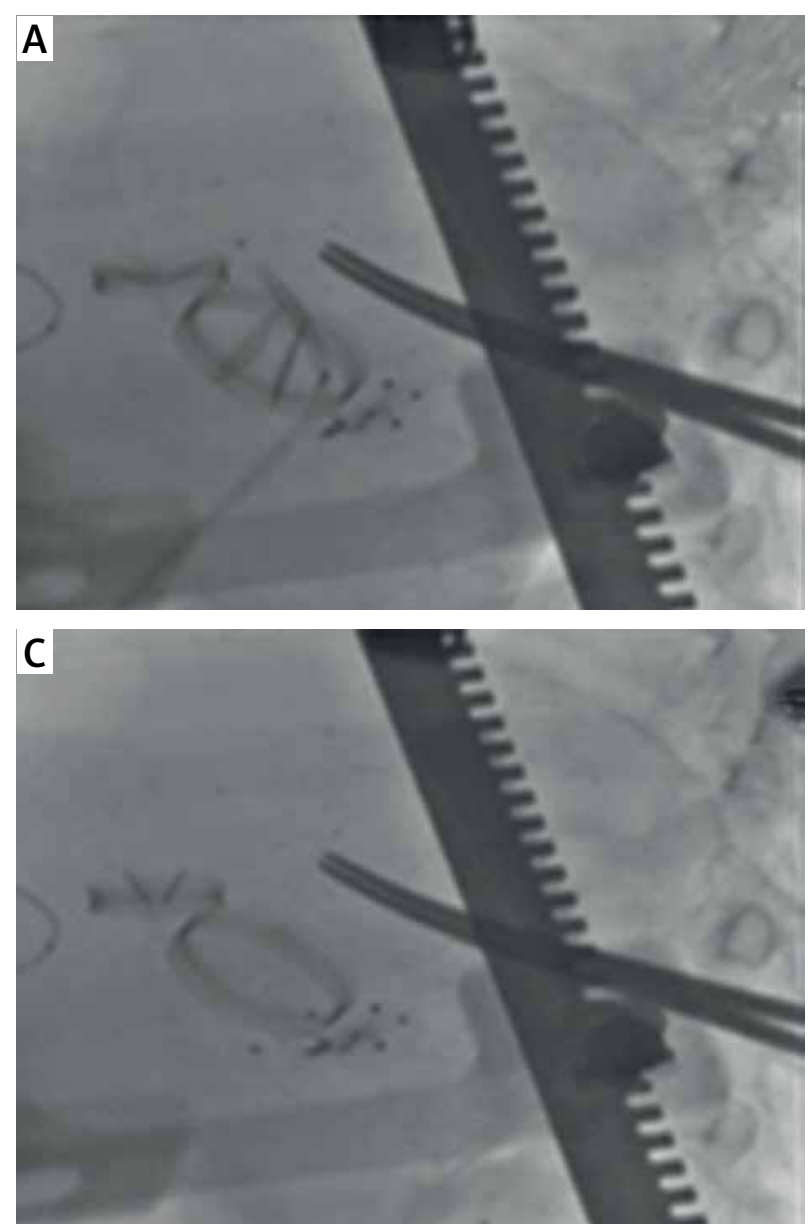

Figure 2. Deployment of four devices to three separate defects, and complete closure of the defects via tran-

sapical access

the stiff wire changed the shape of the defect, passing through the defect became impossible via the catheter. Once the wire was exchanged for a hydrophilic wire, passage was achieved easily. In another case, passage through the PVL was achieved with the hydrophilic wire before wire exchange.

In 1 patient, although the transapical and transseptal access paths were tried, given the interference of the lateral leaflet of the prosthesis after device deployment and the severe calcification of the interatrial septum, the procedure failed, and the patient underwent mitral valve replacement surgery. In another patient, an Amplatzer Vascular Plug III (AVP III) was placed perpendicular to the defect, which could not be pulled back and resulted in residual regurgitation. The technical success rate was 86.6\%. In total, 16 AVP III devices, one Amplatzer Duct Occluder (ADO) device and one Occlutech device were used. One patient died soon after successful device deployment because of advanced heart failure symptoms and multiorgan failure; 1 patient died at 28 days after successful closure because of rectus sheath hematoma; and haemothorax occurred in one patient after successful transapical closure.
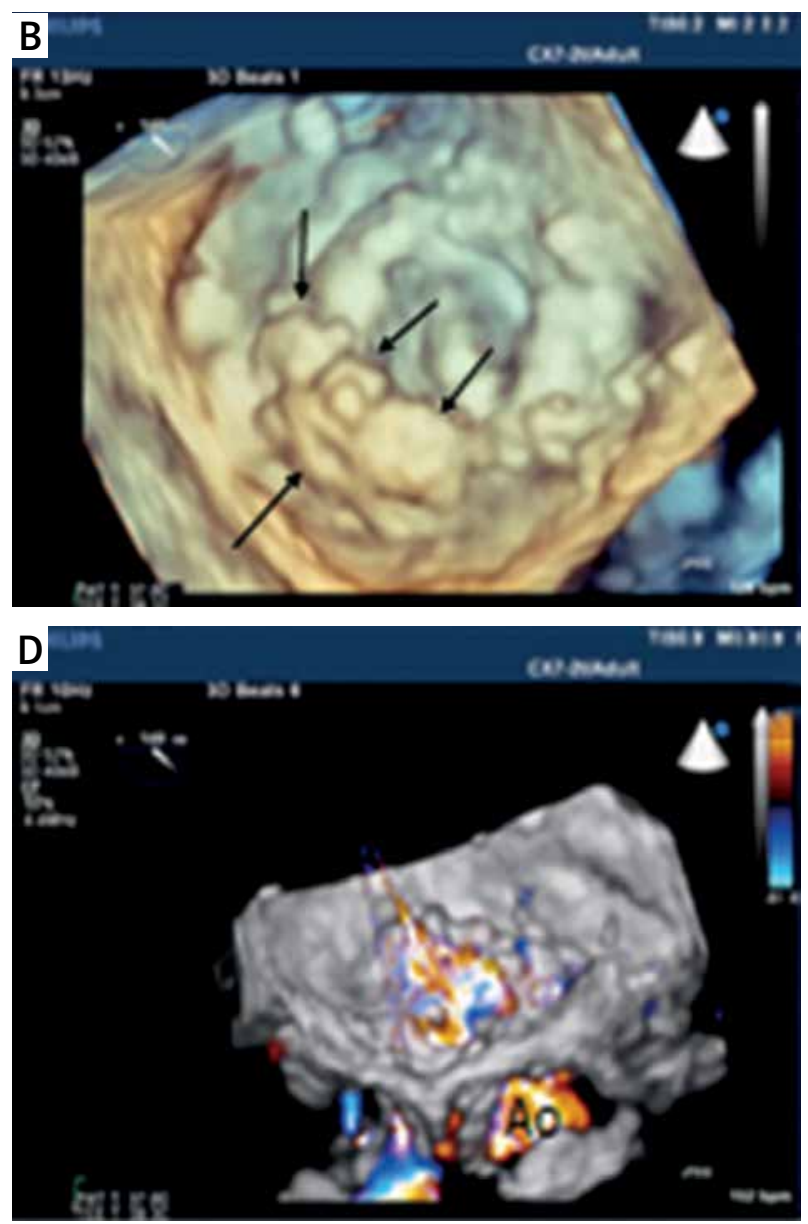

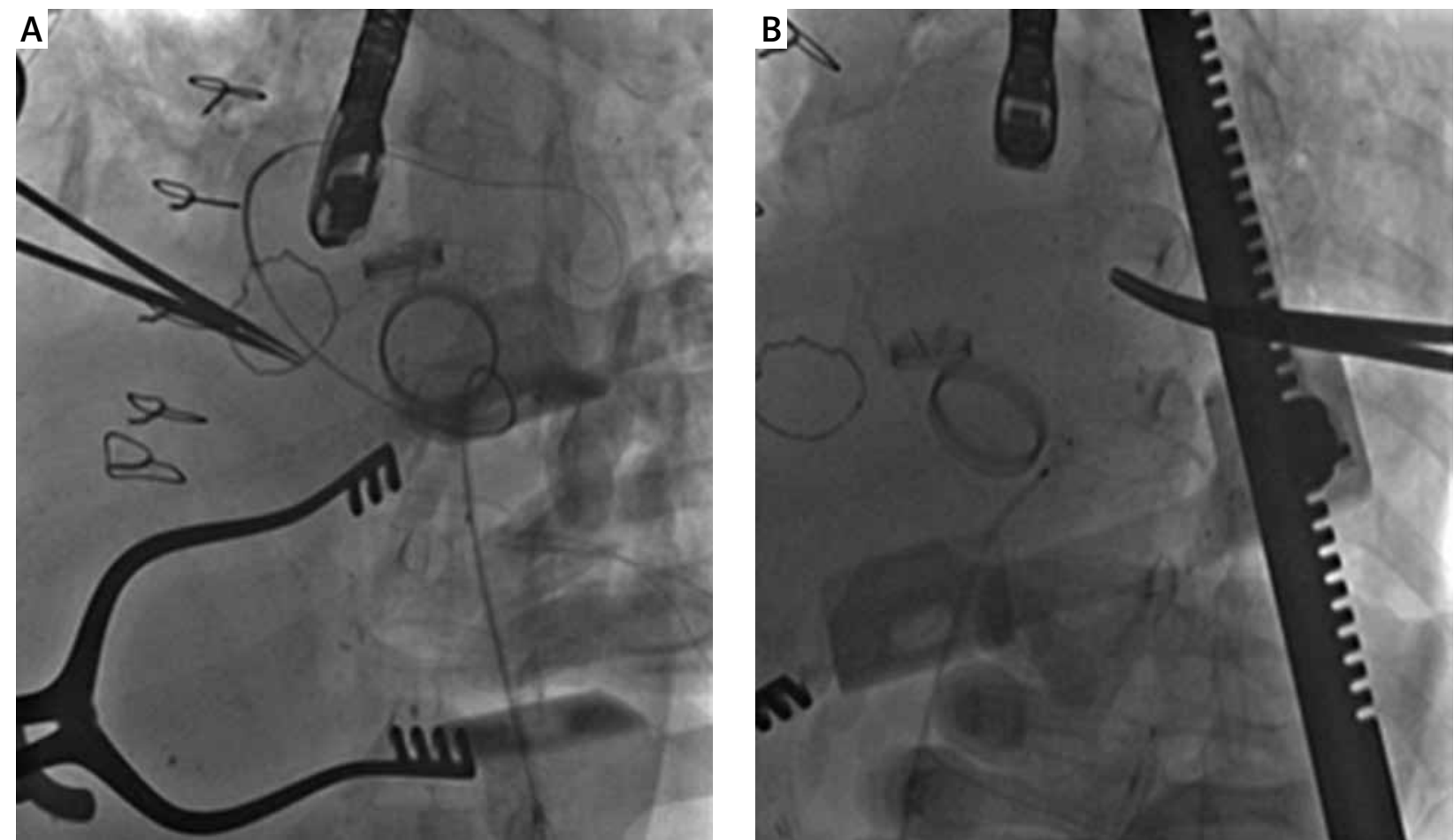

Figure 3. A - Passage through the paravalvular defect using a hydrophilic guidewire; a low-profile catheter coming from the transapical access. B - Deployment of the device

\section{Discussion}

In our case series, we demonstrated that PVL closure through an antegrade or a retrograde approach can be performed safely and effectively without using an AV loop. Transcatheter PVL closure was first reported in 1992 [11]. Since then, because of the inherent morphological variability of PVLs, various techniques and devices have been used to make TPVLC an efficacious and safe procedure [12]. An AV loop through the wire snared and externalised via a femoral artery sheath (if the patient has a mechanical AVR, the initial wire can be exchanged for a stiffer one, such as an Amplatz Super-Stiff, in the left ventricle) facilitates PVL closure and sequential device deployment. However, constructing an AV loop requires more fluoroscopic time and more equipment and has a higher risk of complications. Rihal et al. reported that among 141 defects that were closed in 115 patients, snaring and wire exteriorisation was used in 29 (25\%) patients [13]. Although diverse devices, including umbrella devices, vascular occluding devices and coils, have been used, the most preferred ones are the Amplatzer occluders [14]. However, these devices are often linked to interference with adjacent critical cardiac structures and device embolisation because these devices have larger profiles and stiffer features $[13,14]$. Furthermore, all the sheath and delivery catheter sizes that these devices are compatible with are relatively large (for ASO, 6-12 Fr; VSDO, 5-9 Fr; ADO, 5-7 Fr) [15]. Thus, to provide sufficient support for the device delivery catheter, an AV wire loop is usually needed [8, 14]. Alternatively, the AVP III has a low profile and relatively small retention rims, which may cause less interference with cardiac structures. Additionally, the sheaths and device delivery catheter sizes are smaller than those of ADOs (4-7 Fr) [16], which facilitates the passage of low-profile catheters from the defect without using an AV loop. The feasibility and safety of using AVP III devices have been reported in the literature [2, 16-18]. In our case series, we mostly used AVP III devices, and 16 devices were advanced through 6-Fr or 7-Fr delivery catheters and deployed successfully. Although 10-Fr delivery catheters are used for PLD Occlutech devices newly developed for PVL closure, the AVP III device is available in smaller sizes and has narrower overhanging rims compared with the PLD Occlutech device [19]. In 1 case, closure of a defect with a PLD Occlutech device was also accomplished without using an AV loop. Kilic et al. reported a case series of three patients who underwent percutaneous retrograde closure of PVLs without constructing an AV loop and pointed out the reduced costs, fluoroscopic times and complications [9]. Especially in patients with AVR and MVR, an AV loop can be difficult to perform because of the aortic prosthesis; in our series, half of the patients had AVR and MVR operations, and closure without using an AV loop was an additional advantage in this instance.

These patients were already inoperable and severely symptomatic because of haemolysis or heart failure symptoms. Making the procedural technique easier and 
procedural time shorter may decrease the risk of complications in these patients. Without an AV loop, procedural success can be achieved by the telescopic method, and making the tip of the stiff guidewire a circle for greater stability in the left ventricle especially by transfemoral access, as in transaortic valve implantation procedure, facilitated the procedure without the need for an AV loop.

In our study, the success rate was satisfactory (86\%). In the literature, the technical and clinical success rates ranged from $77 \%$ to $86 \%$ and $67 \%$ to $77 \%$, respectively, and the complication rates were low [2]. In addition to other studies and registries, our series has shown that TPVLC is a safe and feasible technique and can be used without constructing an AV loop.

\section{Conclusions}

The TPVLC is a less invasive and an effective alternative to surgery in symptomatic patients with significant PVLs and high operational risk. The success rates are satisfactory with improving techniques and devices. Procedural success can be achieved without using an AV loop with reduced costs, fluoroscopic times and complications.

\section{Conflict of interest}

The authors declare no conflict of interest.

\section{References}

1. Krishnaswamy A, Kapadia SR, Tuzcu EM. Percutaneous paravalvular leak closure - imaging, techniques and outcomes. Circ J 2013; 77: 19-27.

2. Cruz-Gonzalez I, Rama-Merchan JC, Rodríguez-Collado J, et al. Transcatheter closure of paravalvular leaks: state of the art. Neth Heart J 2017; 25: 116-24.

3. Taramasso M, Maisano F, Latib A, et al. Conventional surgery and transcatheter closure via surgical transapical approach for paravalvular leak repair in high-risk patients: results from a single-centre experience. Eur Heart J Cardiovasc Imaging 2014; 15: 1161-7.

4. Nishimura RA, Otto CM, Bonow RO, et al. 2017 AHA/ACC Focused Update of the 2014 AHA/ACC Guideline for the Management of Patients With Valvular Heart Disease: A Report of the American College of Cardiology/American Heart Association Task Force on Clinical Practice Guidelines. J Am Coll Cardiol 2017; 70: 252-89.

5. García E, Arzamendi D, Jimenez-Quevedo P, et al. Outcomes and predictors of success and complications for paravalvular leak closure: an analysis of the SpanisH real-wOrld paravalvular LEaks closure (HOLE) registry. Eurolntervention 2017; 12: 1962-8.

6. Angulo-Llanos R, Sarnago-Cebada F, Rivera AR, et al. Two-year follow up after surgical versus percutaneous paravalvular leak closure: a non-randomised analysis. Catheter Cardiovasc Interv 2016; 88: 626-34.

7. Taramasso M, Maisano F, Pozzoli A, et al. Catheter-based treatment of paravalvular leaks. EuroIntervention 2016; 12 Suppl X: X55-60.

8. Gafoor S, Steinberg DH, Franke J, et al. Tools and techniques - clinical: paravalvular leak closure. EuroIntervention 2014; 9: 1359-63.
9. Kilic T, Sahin T, Ural E. Percutaneous retrograde transfemoral closure of mitral paravalvular leak in 3 patients without construction of an arteriovenous wire loop. Tex Heart Inst J 2014; 41: 170-3.

10. Zamorano JL, Badano LP, Bruce C, et al.; Document Reviewers: European Association of Echocardiography (EAE): American Society of Echocardiography (ASE): The ASE Guidelines and Standards Committee and the ASE Board of Directors. EAE/ASE recommendations for the use of echocardiography in new transcatheter interventions for valvular heart disease. Eur J Echocardiogr 2011; 12: 557-84.

11. Hourihan M, Perry SB, Mandell VS, et al. Transcatheter umbrella closure of valvular and paravalvular leaks. J Am Coll Cardiol 1992; 20: 1371-7.

12. Noblea S, Basmadjianb A, Ibrahimb R. Transcatheter prosthetic paravalvular leak closure. Cardiovasc Med 2012; 15: 245-52.

13. Rihal CS, Sorajja P, Booker JD, et al. Principles of percutaneous paravalvular leak closure. JACC Cardiovasc Interv 2012; 5: 121-30.

14. Kim MS, Casserly IP, Garcia JA, et al. Percutaneous transcatheter closure of prosthetic mitral paravalvular leaks: are we there yet? JACC Cardiovasc Interv 2009; 2: 81-90.

15. Sánchez-Recalde A, Moreno R, Galeote G, et al. Immediate and mid-term clinical course after percutaneous closure of paravalvular leakage. Rev Esp Cardiol (Engl Ed) 2014; 67: 615-23.

16. Nietlispach F, Johnson M, Moss RR, et al. Transcatheter closure of paravalvular defects using a purpose-specific occluder. JACC Cardiovasc Interv 2010; 3: 759-65.

17. Smolka G, Pysz P, Jasiński M, et al. Multiplug paravalvular leak closure using Amplatzer Vascular Plugs III: a prospective registry. Catheter Cardiovasc Interv 2016; 87: 478-87.

18. Ozkan M, Gürsoy OM, Astarcıoğlu MA, et al. Percutaneous closure of paravalvular mitral regurgitation with Vascular Plug III under the guidance of real-time three-dimensional transesophageal echocardiography. Turk Kardiyol Dern Ars 2012; 40: 632-41.

19. Bedair R, Morgan GJ, Bapat V, et al. Early experience with the Occlutech PLD occluder for mitral paravalvar leak closure through a hybrid transapical approach. Eurolntervention 2016; 12: e1420-7. 